\title{
Analysis of adaptation costs of the organization's personnel
}

\author{
Natalya Nagibina ${ }^{1,}$, Lyudmila $_{\text {Komyshova }}{ }^{1}$, Sergey Fedyunin ${ }^{1}$, and Kirill Sklyarov ${ }^{1}$ \\ ${ }^{1}$ Voronezh State Technical University, Moscow Avenue, 14, Voronezh, 394026, Russia
}

\begin{abstract}
Assessment and analysis of personnel costs of an organization is becoming increasingly important in modern conditions, determining, along with other indicators, the competitiveness of an economic entity. However, the calculation of personnel costs can not be performed based only on the data of traditional accounting for Russian organizations, which determines the relevance of the topic of the proposed work. The purpose of this work is to evaluate and analyze the organization's adaptation costs for employees such as the client Department Manager. As a result of evaluating the productive and unproductive costs of adapting a client Department Manager, it was found that their assessment is possible on the basis of certain assumptions, unproductive adaptation costs exceed productive ones, which does not allow them to be ignored, and the total adaptation costs of one Manager are about 70,000 rubles, which gives an idea of the amount of personnel costs for all management functions. The expediency of accounting for personnel costs for each organization is justified.
\end{abstract}

\section{Introduction}

Currently, Russian entrepreneurs are becoming aware of the fact that an important condition for the competitiveness and efficiency of an organization is the assessment, accounting and planning of personnel costs. If it is the norm for foreign organizations to publish labor costs along with accounting reports to assess the competitiveness of economic entities, this practice is absent in Russia [1].

In addition to the fact that it is not necessary to include personnel costs in the financial statements of organizations, their accounting itself is fraught with some difficulties. It is the norm for Russian organizations to maintain accounting records, which makes it possible to report on taxes and fees in a timely manner. However, accounting does not provide comprehensive information on the organization's personnel costs [2].

Of course, certain accounting accounts are grouped with relevant information, for example, accounts 70 "Calculations with personnel on remuneration", 68.01 "Tax on personal income in the performance of duties of a tax agent", 69 "Calculations on social insurance and security".

If, for example, an organization provides training or professional development of its own employees by third-party specialized organizations, these costs will also be reflected in the cost accounting accounts 20 "Main production", 25 "General production costs" or 26

* Corresponding author: nagibina.natalya@yandex.ru 
"General Economic costs" in the context of the corresponding cost item. However, if the training is conducted by the organization itself, how can we estimate the cost of this process? The last remark applies to almost any HR management function implemented in the enterprise.

\section{Materials and methods}

The organization's personnel costs can be divided into productive and non-productive. Productive costs are related to the assessment of the cost of activities carried out in the organization for the implementation of a particular function of personnel management. For example, the adaptation of newly hired employees may include familiarization with the organization, on-the-job instruction, initial training, assignment to a mentor, and so on.

The assessment of productive adaptation costs for the organization's personnel was based on hourly tariff rates of employees participating in the adaptation process and the duration of their adaptation activities [5].

Non-productive costs include various types of losses of the organization related to the management of the organization's personnel. With regard to adaptation, these will be a decrease in labor productivity, primarily of the newly accepted employee and other employees involved in the adaptation process.

Estimation of unproductive adaptation costs is possible based on assumptions about the percentage of reduction in employee productivity that accompanies the adaptation process and the length of time during which there is a change in labor productivity.

Adaptation costs were estimated for the Manager of the client Department of the organization that sells work clothes, shoes, and personal protective equipment.

The nature and content of the position under consideration directly affects the amount of staff adaptation costs. In modern conditions, when sales of both own and purchased products determine the state of an economic entity, the position in question is present in almost any enterprise. Only the nature of the products sold changes, knowledge of which, together with communication skills, largely determines the professionalism of the Manager of the client Department of any organization.

The company's products are sold using the appropriate software, among which the managers of the client Department are most in demand for "1C: trade Management" and Microsoft Office tools.

However, it is not always possible to attract a candidate who meets the specified requirements. Therefore, the process of adapting new employees is of fundamental importance.

\section{Results}

Suppose the onboarding process for an organization's client department manager consists of three steps, as shown in Figure 1. 
1. Acquaintance with job descriptions,

organizational and historical aspect of the

organization, study of the Sales Standard

\section{Training on occupational health and} safety, training at the workplace

\section{Assignment to a mentor for three months}

Fig. 1. Client manager onboarding process

The first stage of the adaptation process is self-familiarization with job descriptions, the organizational and historical aspect of the organization itself and the study of the Sales Standard, which includes a detailed description of the products sold, taking into account its specificity, quality, properties and a whole range of other indicators.

The entire package of documents intended for acquaintance with a new employee includes $50 \mathrm{~A} 4$ sheets.

If we assume that printing one sheet costs 6 rubles, then the one-time costs for its production are 300 rubles. However, in this case, one should take into account the costs necessary to maintain it in a normal state due to the fact that part of the material is lost, becomes unusable, etc.

Suppose that maintaining reference documents in good condition involves updating ten sheets of text every month. Therefore, the current costs during the three months of the probationary period are 180 rubles.

Thus, the adaptation costs of the organization of the first stage can be represented as a diagram in Fig. 2.

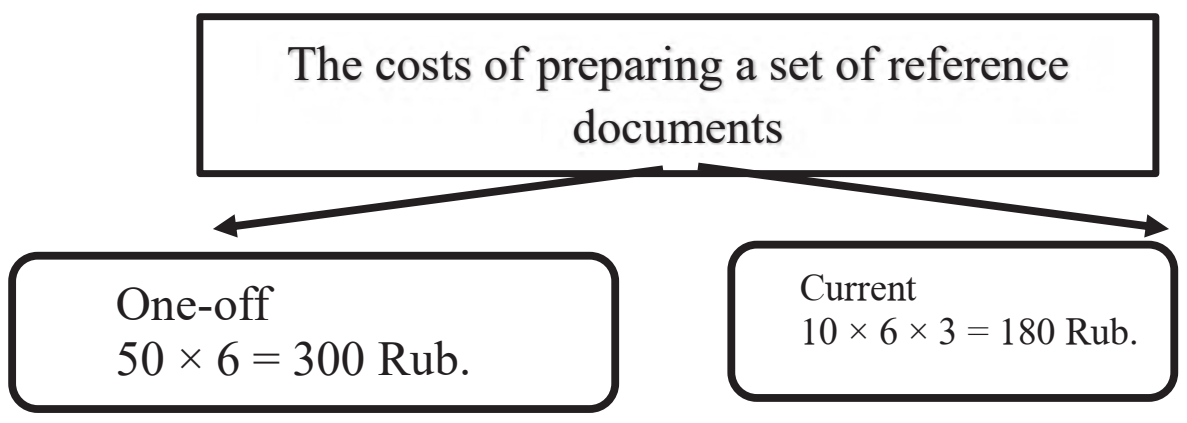

Fig. 2. Organization's expenses for preparing a set of information and reference documents

The second stage of the process of adaptation of a new employee is the instruction on labor protection and safety and on-the-job instruction.

Occupational health and safety instruction is mandatory for every new employee of the organization. It is conducted by an occupational safety engineer within thirty minutes. 
On-the-job training is provided by the head of the client Department-senior Manager.

In this case, a more detailed acquaintance with job descriptions is carried out and their direct connection with the functional responsibilities of the employee is traced.

Special attention is paid to familiarization with the main provisions of the internal regulations, compliance with labor discipline, and compliance with the standards adopted in the organization.

The conclusion provides information describing the system of remuneration at the enterprise, bonuses, allowances, compensation established for this position and traces the relationship between the results of work and its payment.

If instructing on labour protection and safety involves 30 minutes of work engineer on labor protection and workplace training - 45 minutes of operation senior Manager, the cost of these measures can be estimated from the calculation of salaries of employees engaged in instruction, the average number of working days in a month $(22,4)$, and time of duration of the working day ( 8 hours) that are presented in table 1.

Table 1. Adaptation costs of the second stage of the adaptation process

\begin{tabular}{|l|l|c|c|}
\hline \multicolumn{2}{|c|}{ Indicators } & $\begin{array}{c}\text { Occupational health and } \\
\text { safety instruction }\end{array}$ & $\begin{array}{c}\text { On-the-job } \\
\text { training }\end{array}$ \\
\hline Duration $\mathrm{h}$. & 0,5 & $3 / 4$ \\
\hline Executive & $\begin{array}{c}\text { Occupational safety } \\
\text { engineer }\end{array}$ & Senior manager \\
\hline \multicolumn{2}{|l|}{ Salary, rub. } & 30000 & 26000 \\
\hline \multirow{2}{*}{ Hourly tariff rate. } & payment & $30000 / 22.4 / 8$ & $26000 / 22.4 / 8$ \\
\cline { 2 - 4 } & value, Rub. & 167.41 & 145.09 \\
\hline \multirow{2}{*}{ Cost } & payment & $167.41 \times 0.5$ & $145.09 \times 3 / 4$ \\
\cline { 2 - 4 } & value, Rub. & 83.71 & 108.82 \\
\hline Total costs, Rub & & \multicolumn{2}{|c|}{192.53} \\
\hline
\end{tabular}

The final stage of the process of adaptation of the client Department Manager is to attach a mentor to the new employee for the entire period of his probation period, the value of which is set at 3 months.

Any ordinary employee of the client Department who has at least one year of experience can act as a mentor. His duties as a mentor include answering questions, assisting in the performance of official duties, and partially correcting mistakes made by a new employee.

This allows you to estimate how much the mentoring tool costs the organization in the light of the following assumptions.

First, the mentor receives payments from the organization in the amount of 3,000 rubles for each month of work, which is 9,000 rubles for the entire period.

Second, let's assume that the answers to the questions involve 1 hour of work per day of the mentor. Based on the size of the mentor's salary, the average number of working days per month (22.4) and the hourly length of the working day ( 8 hours), an hour of his work costs the organization on average $22000 /(22,4 \times 8)=122,77$ in other words, for three months of mentoring under this cost item, $22.4 \times 3 \times 122.77=8,250$. 14 rubles will be spent.

Further, let's assume that providing assistance to a new employee involves a mentor working for 30 minutes daily, then for the entire period of mentoring, the costs will be 122,77 $/ 2 \times 3 \times 22,4=4125,07$ RUB.

If the correction of errors takes 15 minutes of work per day of the mentor, the cost of this event for three months will be $122,77 \times 3 / 4 \times 22,4==2062,54$ RUB.

The calculation of mentoring costs is summarized in table 2 .

Table 2. Adaptation costs of the third stage of the adaptation process

\begin{tabular}{|l|l|c|}
\hline \multicolumn{2}{|c|}{ Indicators } & Mentoring \\
\hline Duration & mentoring & 3 months. \\
\hline
\end{tabular}




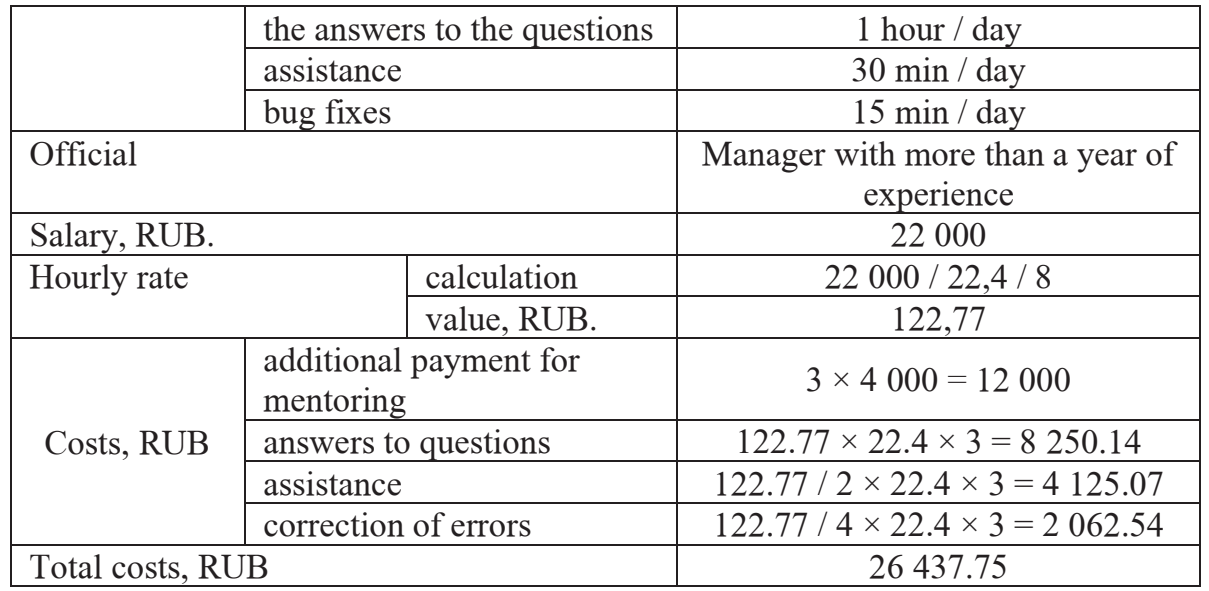

The distribution of mentoring costs is shown in figure 3.

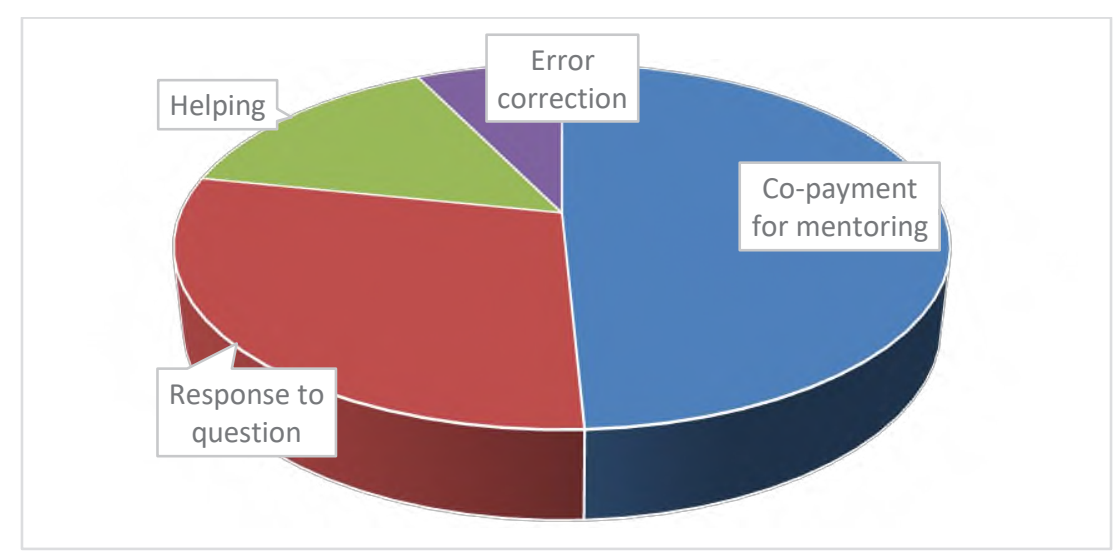

Fig. 3. Cost ratio under the procedure mentoring

Thus, the use of mentoring suggests that about half of the cost of adapting a new employee is due to the organization's additional payments to the mentor. The remaining half of the cost of $29 \%$ is determined by answering questions, $15 \%$ by providing assistance, and $7 \%$ by correcting errors.

The total production costs of Trakt-Voronezh for the adaptation of one Manager of the client Department are presented in table 3.

Table 3. Productive costs of adapting a new employee

\begin{tabular}{|l|l|c|}
\hline \multicolumn{1}{|c|}{ The cost element } & \multicolumn{1}{|c|}{ Assumptions } & Costs, RUB. \\
\hline $\begin{array}{l}\text { 1 Information } \\
\text { support }\end{array}$ & $\begin{array}{l}\text { The price of printing one sheet is 6 } \\
\text { rubles., as well as monthly maintenance } \\
\text { of documents in good condition; printing } \\
50 \text { sheets of A4 format }\end{array}$ & 480.00 \\
\hline
\end{tabular}




\begin{tabular}{|c|c|c|}
\hline $\begin{array}{l}22 \text { Occupational } \\
\text { health and safety } \\
\text { Instruction, } \\
\text { introductory } \\
\text { instruction }\end{array}$ & $\begin{array}{l}\text { Half an hour of work for an occupational } \\
\text { safety engineer and } 45 \text { minutes of work } \\
\text { for a senior Manager with hourly rates of } \\
167.41 \text { and } 145.09 \text { rubles, respectively. }\end{array}$ & 192.53 \\
\hline $\begin{array}{l}3 \text { Co-payment for } \\
\text { mentoring } \\
\text { Response to question } \\
\text { Helping } \\
\text { Error correction }\end{array}$ & $\begin{array}{l}3,000 \text { rubles each for } 3 \text { months } \\
\text { One hour at the hourly rate of } 122.77 \\
\text { rubles. } \\
30 \mathrm{~min} \text {. at the hourly rate of } 122.77 \\
\text { rubles. } \\
15 \mathrm{~min} \text {. at the hourly rate of } 122.77 \\
\text { rubles. }\end{array}$ & $\begin{array}{l}9000.00 \\
8250.14 \\
4125.07 \\
2062.54\end{array}$ \\
\hline \multicolumn{2}{|l|}{ Total: } & 24110.28 \\
\hline
\end{tabular}

The distribution of productive costs for the adaptation of one employee of the client Department is shown in figure 4.

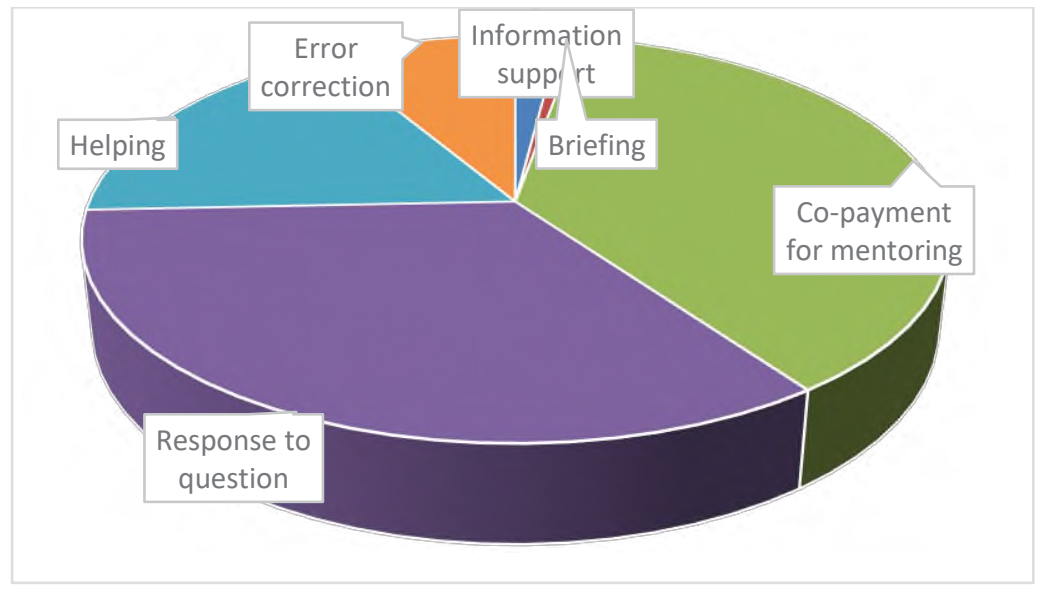

Fig. 4. Distribution of productive costs for adaptation of one employee of the client Department

Thus, the adaptation of a new employee of the client Department requires a total production cost of 24,110. 28 rubles. At the same time, they are mainly represented by the cost of mentoring, which for three months of the probationary period of a new employee will amount to 23,437. 75 rubles. Other items of productive costs are insignificant in comparison with this indicator.

In addition to productive costs, the adaptation process involves reducing the productivity of both the new employee and the mentor. These categories represent the organization's unproductive costs of adapting a new employee.

Let's assume that the process of adaptation of a new employee is accompanied by a monthly $10 \%$ decrease in their productivity during the entire probationary period.

If the revenue from the sale of goods of the organization is about 18,000 thousand rubles per year, and the average number of employees of the organization is 30 people, then the average monthly productivity of one employee will be $18000000 / 12$ / 30 = 50 000 RUB. Then a $10 \%$ reduction in the productivity of the accepted employee within three months will determine the amount of unproductive costs in the amount of 50,000 $\times 0.1 \times 3=15,000$ rubles. 
The duties of a mentor involve reducing their working time by 105 minutes. every day, as he spends an hour answering questions from a new employee, 30 minutes. for assistance and 15 minutes. to correct errors. This value in the total daily working time Fund is $21.9 \%$. Based on this, it can be assumed that the three-month mentoring period of the client Department Manager is accompanied by a $20 \%$ decrease in their productivity on a monthly basis. This leads to unproductive costs in the amount of $15,000 \times 0.2 \times 3=30,000$ rubles, which is twice as much as such costs due to a decrease in the productivity of the new employee.

The total non-productive costs of adapting one employee are shown in table 4.

Table 4. Unproductive costs for adaptation of one employee

\begin{tabular}{|l|l|c|}
\hline \multicolumn{1}{|c|}{ The cost element } & \multicolumn{1}{|c|}{ Assumptions } & Costs, RUB \\
\hline $\begin{array}{l}\text { Lower productivity of a new } \\
\text { employee }\end{array}$ & $\begin{array}{l}10 \% \text { reduction in labor productivity } \\
\text { within three months }\end{array}$ & 15000 \\
\hline Lower mentor productivity & $\begin{array}{l}\text { 20\% reduction in labor productivity } \\
\text { within three months }\end{array}$ & 30000 \\
\hline Subtotal & & 45000 \\
\hline
\end{tabular}

Thus, the non-productive adaptation costs of an organization exceed the productive adaptation costs of a single Manager of the client Department by almost 2 times.

\section{Conclusions}

The assessment of the cost of adaptation of one employee of the client Department allows us to draw the following conclusions:

1. estimation of both productive and non-productive costs for the organization's personnel is possible on the basis of certain assumptions. Although these assumptions can be significantly approximated in the process of organizing targeted accounting for personnel costs within a particular organization, they will still remain assumptions and will introduce some error in the estimates obtained. Consequently, the risk of making ineffective management decisions based on them will increase as the assumptions made are far from reality;

2. the organization's unproductive personnel costs are significantly higher than the productive ones. That is, if only direct costs are taken into account and regulation is carried out on their basis, this can lead to the most unfavorable results for the organization, increasing the total costs of the enterprise due to the fact that a significant part of personnel costs is formed in an area hidden from constant attention;

3. the total cost of the organization only for the adaptation of one new employee was more than 69,000 rubles. This gives an idea of the scale of total personnel costs for all its management functions. Therefore, it is more expedient to conduct at least a rough estimate of the amount of personnel costs of the organization in order to build an effective personnel policy, make sound management decisions and strengthen the financial and economic position of the organization.

\section{References}

1. O. Yu. Minchenkova, personnel Management: budgeting system: textbook, 223 (Moscow, KNORUS, 2018)

2. O. K. Klopova, L. N. Komyshova, Improving human resource management as a factor of economic growth, Region: systems, Economics, management, 3(30), 91-98 (2015) 
3. A. Ya. Kibanov, E. A. Mitrofanov, I. A. Esaulova, Economics of personnel management: the Textbook, 427 (Moscow, INFRA-M, 2015)

4. N. A. Nagibina, Development of a database on accounting for the cost of using workers ' labor. Materials of the all-Russian scientific and practical conference "Academic Zhukovsky readings". - Voronezh: VUNTS air force "Military and air Academy. Professor I. E. Zhukovsky and Y. A. Gagarin", 54-58 (2013)

5. Economics and sociology of labor: Textbook, edited by doctor of Economics, prof. A. ya. Kibanov, 584 (Moscow INFRA-M, 2017)

6. T. V. Alesinskaya, D. V. Arutyunova, V. G. Orlova, I. V. Ilin, S. V. Shirokova, Conception BSC for investment support of port and industrial complexes Academy of Strategic Management Journal, 16(1), 10-20 (2017)

7. I. V. Ilin, A. V. Izotov, S. V. Shirokova, O. V. Rostova, A. I. Levina, Method of decision making support for it market analysis Proceedings of 2017 20th IEEE International Conference on Soft Computing and Measurements, SCM 2017, 7970732, 812-814 (2017)

8. I. Ilin, V. Vasilenok, R. Marchenko, Use of renewable energy and tax burden on CO2 emissions in industrial enterprises, E3S Web of Conferences, 110, 0210 (2019)

9. T. Gorokhova, et al. E3S Web of Conferences 135, 04069 (2019) doi:10.1051/e3sconf/201913504069 